\title{
Covid-19: Experts question guidance to reuse PPE
}

\author{
Abi Rimmer
}

The BMJ

Doctors have expressed concern over new guidance from Public Health England that recommends reusing personal protective equipment in the face of shortages. ${ }^{1}$

The guidance, which also recommends alternatives for unavailable equipment, has been seen as an admission by the government of the PPE shortages facing healthcare staff. Rob Harwood, chair of the BMA's Consultants Committee, said, "This guidance is a further admission of the dire situation that some doctors and healthcare workers continue to find themselves in because of government failings.

"Telling staff to use aprons in the place of gowns directly contravenes both Public Health England's previous guidance and that of the World Health Organization. This is guidance that's there to help keep healthcare workers and their patients out of harm's way."

The new guidance states that fluid resistant surgical masks and disposable respirators (FFP3/FFP2/N95) can be reused if they are neither damaged nor soiled and if they are folded such that the outer surface is held inward and against itself and stored in a sealable bag. It also says that in the absence of fluid resistant, disposable gowns or coveralls, reusable items such as washable laboratory coats or long sleeved patient gowns can be used.

Neil Mortensen, president elect of the Royal College of Surgeons, said that the college was deeply disturbed by the changes to the guidance, which he said were issued without consultation with expert medical bodies.

"After weeks of working with PHE and our sister medical royal colleges to get the PPE guidance right, this risks confusion and variation in practice across the country," Mortensen said. "The new guidance implies that, even in the operating theatre, surgeons and their teams may not require proper PPE. This is simply unacceptable."

Michael Griffin, president of the Royal College of Surgeons of Edinburgh, said, "Asking frontline staff to reuse equipment or work without full length gowns puts clinicians and patients at risk, particularly in surgical settings."

In a joint statement the Faculty of Intensive Care Medicine, the Intensive Care Society, the Association of Anaesthetists, and the Royal College of Anaesthetists said that the guidance was confirmation by a government agency of critical shortages of PPE. It meant that those who delivered care "may have to make difficult decisions that balance the health of patients with that of healthcare professionals," they said.

The organisations added that if shortages continued or worsened, their members would face increasingly difficult decisions. "This will involve balancing the safety of patients against their personal safety and that of other staff, those they return home to after work, and patients they may treat in the future."

They said that they would support doctors who decided they could not work because of inadequate PPE. They advised their members that in such an event they comply with GMC guidance by making "a clear contemporaneous record of your decisions in the event that a concern is raised."

A Department of Health and Social care spokesperson said, "We are working round the clock given the global shortage of gowns and other PPE to secure the NHS and the social care sector the equipment they need.

"New clinical advice has been issued to make sure that if there are shortages in one area, frontline staff know what PPE to wear instead to minimise risk. This has been reviewed by the Health and Safety Executive and is in line with WHO and CDC [the US Centers for Disease Control and Prevention] guidance on PPE use in exceptional circumstances.

"There is a 24 hour NHS run helpline where NHS and social care workers can call to report shortages in supply, and it is crucial the relevant guidance for protective equipment is followed closely."

\section{\#properPPE}

The BMS A \#properPPE campaign is calling for healthcare workers to be given the appropriate level of PPE. We are calling for doctors to have the correct PPE for each clinical setting, for PPE of sufficient quality and quantity, and for doctors to be given what they need to make them feel safe.

Share your stories with us on social media by using \#properPPE or by email at newsdesk@bmj.com. We want to hear about your experiences so that we can push governments to act.

1 Public Health England. Considerations for acute personal protective equipment (PPE) shortages. 17 Apr 2020. https://www.gov.uk/government/publications/wuhan-novelcoronavirus-infection-prevention-and-control/managing-shortages-in-personal-protectiveequipment-ppe.

Published by the BMJ Publishing Group Limited. For permission to use (where not already granted under a licence) please go to http://group.bmj.com/group/rights-licensing/ permissions 